\title{
Uma perspectiva latino- americana para as políticas sociais: quão distante está o horizonte?
}

\author{
A Latin American perspective for social \\ policies: how far is the horizon?
}

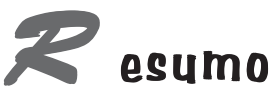

Este artigo propõe-se a analisar as políticas sociais na América Latina em suas determinações fundamentais operadas pela ordem capitalista, a partir, porém, de um ângulo original: o que reconhece a dependência como principal contradição determinante dos problemas da região. Para decifrar as determinações fundamentais das políticas sociais e sua viabilidade histórica no contexto dos arranjos políticoinstitucionais contemporâneos na América Latina, o referencial teórico-metodológico de análise deriva diretamente do pensamento de Marx. Nessa medida, a reflexão marxiana e o pensamento social latinoamericano caminharam juntos com um amplo movimento político de índole e conteúdo libertários, que encontrou nas formulações sobre a teoria da dependência seu momento de maior conexão em termos de práxis política. $\mathrm{O}$ caráter crítico desse pensamento e sua vinculação com o marxismo foram fundamentais para consolidá-lo como uma das melhores tradições críticas para interpretar e, o que é mais importante, transformar a realidade latino-americana

Palavras-chave: América Latina, políticas sociais, Teoria Marxista da Dependência.

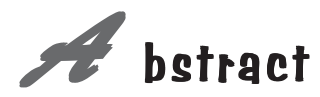

This article proposes to analyze social policies in Latin America in their fundamental determinations as operated by the capitalist order, from an original angle: one which recognizes dependency as the principal determining contradiction of the region's problems. To decipher the basic determinations of the social policies and their historic viability in the context of contemporary political-institutional arrangements in Latin America, the theoretical-methodological reference of the analysis is derived directly from Marx's thinking. To this degree, the Marxist reflection and Latin American social thought have proceeded together with a broad political movement of libertarian content and temperament, which found in the formulations about the theory of dependence their moment of greatest connection in terms of political praxis. The critical character of this thinking and its link with Marxism were fundamental for consolidating it as one of the best critical traditions to interpret and, more importantly, transform Latin American reality.

Key words: Latin America, social policies, Marxist Theory of Dependency.

\section{Beatriz Augusto de Paiva}

Doutora em Serviço Social pela Pontifícia Univ. Católica de São Paulo-PUC/SP.

Professora do Dep. de Serviço Social da Universidade Federal de Santa CatarinaUFSC.

\section{Nildo Domingos Ouriques}

Doutor em Economia pela Univ. Nacional Autónoma de México - UNAM.

Professor do Dep. Economia da UFSC.

Coordenador do Observatório LatinoAmericano (OLA/UFSC). 
...no dia ou noite em que o esquecimento estale salte em pedaços ou crepite as recordações atrozes e as de maravilhamento quebrarão as trancas de fogo arrastarão afinal a verdade pelo mundo e essa verdade será a de que não há esquecimento Mário Benedetti

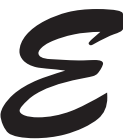

ste artigo se propõe a analisar as políticas sociais em suas determinações fundamentais operadas pela ordem capitalista, porém a partir de um ângulo original: o que reconhece a dependência como principal contradição e problema da região, tema constante do programa de pesquisa do Observatório Latino-Americano (OLA/UFSC) ${ }^{1}$.

Assim, a perspectiva latino-americana aqui adotada pretende demonstrar as razões pelas quais os modelos teóricos e os arranjos institucionais de políticas públicas, que tentem reproduzir o modelo social europeu, malgrado sua inequívoca gênese história, serão sempre insuficientes na explicação e no enfrentamento da questão social nos países latino-americanos. Neles a realidade singular, nos marcos da modernização capitalista, engendra padrões e regulações bastante distintas dos países centrais, distinção esta que repõem em escala ampliada as contradições da sociedade de classes e, nessa medida, obstáculos e desafios ímpares para luta pelos direitos sociais e sua tradução e termos de políticas públicas.

Nesta crítica das políticas sociais não se pode perder de vista as tarefas que a construção da soberania dos povos e países da América Latina impõe: a plena socialização da riqueza e o exercício do poder, nos seus níveis políticos, culturais, econômicos e sociais. Assim, nas trilhas abertas pela luta dos povos latino-americanos em direção à emancipação humana, a análise crítica das políticas sociais tem como horizonte a realização de uma práxis teórica e política potencializada pelas estratégias organizativas populares de pertencimento a um projeto coletivo de classe, radicalmente democrático, portanto revolucionário e anticapitalista (PAIVA, 2005, p. 116), sempre orientada por seu compromisso emancipatório, liberador, pela práxis e pelas idéias que divulgavam e defendiam a liberação e constituição da Pátria Grande, para dizê-lo com Bolívar, ou de uma Segunda Emancipação, com Mariátegui (OURIQUES, 1995).

Para decifrar as determinações fundamentais das políticas sociais e sua viabilidade histórica no contexto dos arranjos político-institucionais contemporâneos na América Latina, o referencial teórico-metodológico de análise deriva diretamente do pensamento de Marx. Nessa medida, a reflexão marxiana e o pensamento social latino-americano caminharam juntos com um amplo movimento político de índole e conteúdo libertários, que encontrou nas formulações sobre a teoria da dependência seu momento de maior conexão em termos de práxis política, já que, na América Latina, o caráter crítico desse pensamento e sua vinculação com o marxismo foram fundamentais para consolidá-lo como uma das melhores tradições críticas para interpretar e, o que é mais importante, transformar a realidade latino-americana.

Em resumo, a análise marxista aqui realizada está isenta do eurocentrismo que durante muito tempo também afetou as melhores contribuiçoes dos marxistas no Brasil, mas também se verificou, ainda que em escala menor, em outros países latino-americanos. Em conseqüência, o conceito de dependência é central na elaboraçao de políticas sociais como também na interpretação de qualquer aspecto da vida social que se pretenda concreto relativamente às codições de vida dos povos latino-americanos.

\section{Determinações das políticas sociais no capitalismo}

O primeiro registro histórico-conceitual a ser proposto é a compreensão de que as políticas sociais - conforme uma das formas típicas de intervenção estatal - são originárias não só das transformações determinadas geneticamente no trânsito da fase concorrencial do capitalismo à fase monopolista, ocorrido na passagem do século xIx para o xx, mas, também - em estreita relação com isso - pela dinâmica das lutas políticas que se expressam nos processos de ampliação dos direitos sociais. Trata-se de um processo capturado pelo melhorismo, nos termos que designa Fernandes (1985, p. 49), ao questionar: "Uma nova utopia - a de uma sociedade civil igualitária sob o capitalismo? É evidente que não. O melhorismo só toma conta das cabeças radicais movidas pela fantasia".

A captura da luta de classes pela lógica dos ganhos legais no campo das políticas sociais é fruto, portanto, de um incipiente estágio da luta de classes, que precisa ser reconhecido como tal, ainda que a consciência liberal que domina os intelectuais e parte importante dos movimentos sociais tente escamotear tal renúncia como uma conquista da cidadania. A idéia de uma plenitude de direitos sociais é totalmente improvável no capitalismo operado nos países centrais, é ainda mais inconcebível nas condições de periferia do sistema capitalista mundial. Como o poeta já disse, "ninguém, ninguém é cidadão" 2 .

No que diz respeito às transformações processadas na fase inaugurada com a monopolização intensa do capital, a luta por maiores lucros, a concentração de capital nas mãos de capitalistas mais poderosos, o aumento da produtividade, assim como fatores conjunturais os mais complexos, como a crise que eclodiu no primeiro pós-guerra, foram alguns dos elementos que propiciaram a formação dos grandes monopólios e sua disseminação em nível global nesse estágio de mundialização do capital financei- 
ro, com poucos, porém grandes e poderosos, conglomerados de empresas monopolistas. Esta monopolização demonstrou que a possibilidade de um equilíbrio entre os múltiplos capitais singulares, no interior do capital em seu conjunto - equilíbrio que antes era requisitado no nível do mercado, através da formação de uma taxa média de lucro -, tornou-se cada vez mais difícil.

O movimento conflituoso e contraditório que coloca permanentemente em xeque a hegemonia do capital em seu conjunto ${ }^{3}$ exigiu a modificação da intervenção estatal na economia, no sentido de que fosse administrado o processo de acumulação emergente e as implicações sociopolíticas que daí decorressem. O financiamento público de parte do capital variável, para favorecer o incremento da acumulação privada, consistiu, então, em uma engrenagem modelar no desenho do Estado capitalista, sobretudo dos países centrais nessa fase monopolista, desde o segundo quartel do século XX.

A política social, como mecanismo que socializa os custos da reprodução da força de trabalho para o conjunto da sociedade, é uma dessas estratégias acionadas nessa nova fase da regulação capitalista. Tornada não somente necessária, devido ao acirramento da luta de classes, mas sobretudo possível, com a expansão da extração da mais-valia, é fundamental para o aproveitamento produtivo do excedente econômico a ser valorizado.

Em estudo clássico acerca da questão do aproveitamento lucrativo do excedente de capital produzido, Baran e Sweezy (1966, p. 223) revelam que existe uma incapacidade crônica do sistema para absorver o excedente que efetivamente produz, pois "Somente no capitalismo monopolista o 'excesso' surge como problema geral afetando a todos, em qualquer época". Para eles, um dos problemas em relação a esse excedente - ou seja, a diferença para mais entre o que a sociedade produz e os custos dessa produção - incide sobre as decisões acerca do seu aproveitamento: trata-se de impedir que ele fique sem utilização produtiva, e, com isso, perca a capacidade de abreviar as crises cíclicas do sistema capitalista.

Nas economias centrais, realizar lucrativamente o excedente significa, dentre outros aspectos, manter o salário dentro dos parâmetros aceitáveis à reprodução do capital e, ao mesmo tempo, criar um mercado potencial onde o excedente possa ser realizado, nos limites objetivos da ordem burguesa. Nessa perspectiva, as políticas sociais - fortemente inscritas na regulação salarial formal - desempenham um papel estratégico na manutenção dos esquemas de coesão social, mas também contribuem para a organização do mercado capitalista, ao favorecer a participação dos trabalhadores como consumidores. Essa é uma dinâmica inteiramente distinta daquela que se processará nas economias exportadoras latino-americanas. Como mostra Marini (2000, p. 132), "nascida para atender as exigências da circulação capi- talista, cujo eixo de articulação está constituído pelos países industriais e centrado então sobre o mercado mundial, a produção latino-americana não depende, para sua realização, da capacidade interna de consumo". Esta determinação específica será decisiva para o deciframento das contradições que cercam o campo das políticas sociais na América Latina.

É necessário precisar as circunstâncias em que o Estado recorre a e aciona tais mecanismos, conectados com a sofisticada estrutura de dominação econômica e política burguesa. Uma das proposições mais importantes sobre essa questão enfatiza que o ordenamento das estratégias do Estado obedece precisamente à necessidade de garantir a integração da força de trabalho na relação de assalariamento, portanto submetida à ordem do capital. Nesse sentido, Netto (1992, p.27) observa que a marca essencial da funcionalidade da política social do Estado burguês, em sua ordem capitalista monopólica, "[...] se expressa nos processos referentes à preservação e ao controle da força de trabalho ocupada, mediante a regulamentação das relações capitalistas/trabalhadores". Ainda aqui Marini (2000, p. 119) esclarece que "[...] o uso da força para submeter a massa trabalhadora ao capital diminui à medida que passam a operar mecanismos econômicos que consagram essa subordinação". Entretanto, como se observará mais adiante, a expansão da modernização capitalista de tipo monopolista na América Latina apresentará uma aguda e singular contradição:

Chamada a coadjuvar a acumulação do capital com base na capacidade produtiva do trabalho nos países centrais, a América Latina teve que fazê-lo mediante uma acumulação fundada na superexploração do trabalhador. Nesta contradição radica-se a essência da dependência latino-americana (MARINI, 2000, p. 132).

Tal configuração histórico-social sobre a qual se assenta a economia exportadora será decisiva para explicar a natureza específica das políticas sociais nos países latino-americanos, no que desafia abertamente os esquemas analíticos eurocêntricos predominantes, a partir dos quais sobressaem duas mistificações: a primeira, que aparece como subproduto das 'políticas e partidos progressistas', reivindica políticas sociais de corte social-democrata, iludindo o fato de que mesmo a melhor política social ainda está no âmbito de reprodução da força de trabalho como mercadoria, logo, aprisionada pela lógica da exploração e dominação burguesas. Tal perspectiva demanda a composição de políticas sociais assentadas no direito ao trabalho, sem questionar que tal relação corresponde a um estágio histórico de exploração do trabalho pelo capital conseqüentemente avesso a qualquer pretensão dignificante, como se costuma atribuir. 
A segunda mistificação é decorrente da primeira e implica no reconhecimento de uma especificidade latinoamericana: na medida em que a maioria da força de trabalho ${ }^{4}$ na América Latina é submetida à superexploração, os direitos sociais a ela destinados só podem corresponder a esquemas próprios. Ao contrário das configurações diretamente contributivas, conforme os modelos clássicos das sociedades que experimentaram o pleno emprego ou que se encontram no centro do mercado mundial. A América Latina possui cerca de dois terços da sua força de trabalho submetida à informalidade, desemprego estrutural alto, salários baixíssimos.

Todavia, referenciar o estatuto político de direitos sociais para as massas populares, numa cena acadêmica e política que só reconhece os direitos sancionados pelo mercado capitalista, ou que estejam imbricados diretamente na dinâmica de reprodução do capital, não é uma empreitada simples. Contraditoriamente, os especialistas nas políticas sociais, sejam conservadores ou não, atribuem um desvalor às políticas sociais voltadas aos segmentos populares não só por trazerem a maldição do assistencialismo ou do populismo (seja lá o que for isso), sempre invocados quando se trata de destinar fundo público às massas expropriadas e superexploradas, mas também porque representam desperdícios, ilegítimas do ponto de vista do gasto social.

Para além da indignação aos padrões erráticos, pontuais e alienadores que predominam nas políticas sociais - este não é o centro da questão - do que se trata é refletir sobre a relação entre política social e reprodução da força de trabalho na América Latina, sem negligenciar a natureza específica da dependência nos países periféricos, de maneira a apontar os limites sobre os quais se reproduzem as mistificações nas análises correntes sobre o tema.

\section{Políticas sociais e luta de classes}

Um vínculo igualmente determinante das políticas sociais, em parte contraditório ao anterior, corresponde ao seu registro histórico-político, no qual se observa que sua implantação resulta também dialeticamente da luta dos trabalhadores por direitos sociais. Se o excedente econômico do capital sustentou o financiamento das políticas sociais em seu estágio mais dilatado, certamente atendeu à intensa e demorada luta política dos trabalhadores. Essa determinação política, e não apenas econômica, das políticas sociais já havia sido ressaltada numa importante (embora nem sempre lembrada) afirmação de Marx (1956, p.354): “A lei da jornada de dez horas [a restrição legal da jornada de trabalho] não foi apenas um grande êxito prático; foi a vitória de um princípio; pela primeira vez, em plena luz do dia, a economia política burguesa sucumbiu ante a economia política da classe operária”.
Ao desvelar o caráter social subjacente ao processo de produção de mercadorias, Marx comprovou que o capital não é uma coisa material, mas sim uma relação social que se concretiza através da interação com o outro termo da relação, o trabalho assalariado. A articulação entre as políticas sociais públicas e o processo de regulamentação da força de trabalho revela um aspecto fundamental da lógica capitalista, que é o controle das relações sociais de produção, seja no nível ideológico ou político, seja no nível da dominação econômica em si. Como foi sinalizado, existe um vínculo genético entre as políticas sociais no capitalismo e os processos de legitimação que o Estado e as classes dominantes programam junto às classes assalariadas.

As estratégias de intervenção do Estado, organizadas de acordo com as exigências da acumulação ampliada do capital, não são alheias à dimensão de luta de classes em cada sociedade e em cada época determinada. É sabido que Marx, na célebre Introdução de 1857 (1974, p.109131) à Contribuição à Crítica da Economia Política, acentua o primado da produção sobre a circulação e a distribuição, na totalidade concreta de um modo de produção dado. Porém, como pensador dialético, Marx insiste não só na ação recíproca que existe entre essas três determinações fundamentais da esfera da economia, mas também no fato de que qualquer totalidade, implicando múltiplas determinações, constitui uma unidade contraditória, sendo precisamente dessa contradição que resultam os processos dinâmicos de estruturação e de desestruturação dessa totalidade.

Nessa totalidade contraditória há uma questão central que deve ser mencionada, ainda que rapidamente: em que medida a discussão da propriedade e suas conexões com a reprodução das relações de exploração podem ser referências fundamentais para se pensar e atuar no campo das políticas sociais?

Este questionamento não é desimportante nem extemporâneo porque é voz corrente nos meios burocráticos e acadêmicos pleitear para a política social um estatuto exclusivamente normativo, como mero mecanismo de intervenção estatal, exclusivamente técnico. Tal distorção, obviamente, atende à lógica de esterilização da conflitualidade própria do antagonismo permanente entre capital e trabalho, que ademais encontra na propriedade privada - fundiária e dos meios de produção - sua base material estrutural.

Por outro lado, se a política social se inscreve como um processo determinado pelos antagonismos fundamentais da sociedade capitalista (classe, gênero e etnia), é preciso reconhecer que alterações na correlação de forças no âmbito das relações de reprodução social, decorrentes dos processos políticos concretos em torno dos direitos sociais, não possuem capacidade orgânica de atuar decisivamente junto às estruturas, aos aspectos essenci- 
ais da luta de classes, em termos do combate à exploração capitalista e às relações de propriedade e de poder sobre as quais ela se assenta. "As relações de propriedade privada são o trabalho, o capital e as interconexões entre os dois" diz Marx (2002, p.129), como explicitação da centralidade da propriedade tal qual mediação particular na totalidade do processo de produção capitalista.

Mesmo que pontualmente, a remissão a essa análise torna-se valiosa para auxiliar na recomposição das contradições que perpassam a relação entre as esferas da produção e da reprodução social da riqueza e da pobreza, cenário concreto que estabelece os parâmetros de regulação do conflito entre capital e trabalho, na forma de políticas sociais. A mútua interconexão entre as duas dimensões do processo de valorização encontra, pois, na manutenção das relações de propriedade na sua forma capitalista assim privada, a demarcação objetiva para sua reprodução. Essa passagem de Marx (2002, p.138-9) é elucidativa a esse respeito:

A propriedade privada material, imediatamente perceptível, é a expressão material e sensivel da vida humana alienada. O seu movimento - a produção e o consumo - é a manifestação sensivel do movimento de toda a produção anterior, quer dizer a realização ou realidade do homem. A religião, a família, o Estado, o Direito, a moral, a ciência, a arte, etc., constituem apenas modos particulares da produção e submetem-se à sua lei geral. A eliminação positiva da propriedade privada, tal como apropriação da vida humana, constitui, portanto, a eliminação positiva de toda a alienação [...] à sua existência humana, ou seja, social.

Não há ilusões quanto à impossibilidade ou incapacidade de alteração do estatuto de propriedade privada no contexto da institucionalidade burguesa, ou seja, da organização dos meios de produção sobre o princípio da propriedade socializada. Isso demarca um limite intransponível ao potencial transformador das políticas sociais, aprisionadas que estão ao âmbito das relações sociais de reprodução capitalista. Porém, tal limite não invalida a contraditoriedade que a disputa política entre as classes sociais expressa em torno dos processos de expansão dos direitos sociais e das conseqüentes respostas que o Estado elabora em termos do enfrentamento da questão social nos países da região.

Logo, a impossibilidade de se alterar o estatuto de propriedade por meio das medidas de políticas públicas não suprime o potencial político do processo de disputa decorrente da luta pelos direitos sociais para as maiorias. O protesto social em curso na região, como resposta ao conflito aberto das maiorias exploradas com o capital pelo acesso à riqueza socialmente produzida, dentro dos limi- tes institucionais do Estado burguês, encontra nas políticas sociais um campo impregnado de desafios, dos pontos de vista teórico e político. Assim, como explicar os processos de transformação social na América Latina, desde a Revolução Cubana até a Revolução Bolivariana na Venezuela, sem o exame acurado crítico das políticas sociais em sua formação latino-americana?

Nessa medida, a natureza orgânica das políticas sociais para a funcionalidade da ordem capitalista não the esvazia o potencial estratégico, na condição de importante suporte do processo de saturação das contradições econômicas e políticas presentes na sociedade. É nessa dimensão que as políticas sociais, embora incapazes de portar por si sós a envergadura necessária para processar a ultrapassagem do estatuto da propriedade privada, revelam-se como mediações fundamentais para a luta, no âmbito do reconhecimento progressivo dos direitos sociais dos trabalhadores.

Embora não apareça como conflito direto entre capital e trabalho, o que está em jogo é o próprio estatuto de propriedade privada, sobre o qual são praticadas e sancionadas as regulações econômicas da produção e acumulação capitalistas. Assim, nos é facultado dizer que se põem as seguintes alternativas: ou 1) as transformações ocorridas no processo distributivo são minimizadas ou abandonadas, restabelecendo-se o primado exclusivo da lógica da produção capitalista; ou 2) essas transformações da distribuição permitem uma ruptura com essa lógica, criando as condições para a emergência de um novo modo de produção.

Mas não se trata de acatar essa polarização binária como únicos caminhos de enfrentamento da luta no campo do acesso à riqueza social. Talvez não seja impróprio dizer que também Trotski (apud CHESNAIS, 1999, p.10) chegou a reconhecer a dimensão político-institucional da luta operária no jogo democrático, insistindo na qualificação dessa conforme um momento importante na construção da democracia operária no interior do Estado capitalista:

[...] Durante várias décadas, no interior da democracia burguesa, servindo-se dela e' lutando contra ela', os operários edificaram as suas fortificações, suas bases, seus focos de democracia proletária: sindicatos, partidos, clubes de educação, organizações esportivas, cooperativas, [...] bases de apoio da democracia ao proletariado para a via revolucionária (grifo nosso).

Igualmente importante, ao se pretender atingir um grau maior de concreticidade, é determinar a lógica da relação entre o Estado e a sociedade civil, naquele contexto político mais abrangente e mais concreto no qual as classes sociais fundamentais, através do conflito político, articulam-se tendo em vista o enfrentamento das questões decisivas, que certamente surgem na esfera da produção e reprodução das relações sociais. Como Marx (1956, p.35) observou: 
É preciso distinguir sempre entre as mudanças materiais ocorridas nas condições econômicas de produção e que podem ser apreciadas com a exatidão própria das ciências naturais, e as formas jurídicas, políticas, religiosas, artísticas ou filosóficas, numa palavra, as formas ideológicas em que os homens adquirem consciência desse conflito e lutam para resolvê-lo.

Cabe ressaltar que esse tipo de ação do Estado está condicionado não só pelo que Marx definiu como "mudanças materiais ocorridas nas condições econômicas de produção", mas também pelo desenvolvimento das lutas de classes, pelo movimento social organizado, pelas disputas dos partidos no âmbito da implementação dos pertinentes interesses de classe e, complementarmente, pela adoção das regras, medidas e dinâmicas socioinstitucionais, através das quais se estrutura o regime político - democrático ou não - de um país. Em suma, foi o que Marx chamou de "formas ideológicas" (jurídicas, políticas, etc.), nas quais os homens e mulheres tomam consciência e encaminham a solução dos conflitos econômicos.

Desta forma, cabe pensar as políticas sociais para além do horizonte da mera estratégia de acomodação de conflitos ou caridade social, o que requer referenciá-las no processo de disputa política pelo excedente econômico real pelas massas historicamente expropriadas, de maneira que as políticas sociais não possibilitem somente reduzir as manifestações mais agudas da pobreza, através da ampliação dos serviços sociais básicos e do seu acesso, mas, sobretudo, permitam que

"[...] a política social torne-se um instrumento de transformação social que mobiliza e organiza as massas a partir de seus interesses mais fortes" (OURIQUES, 2005, p.140).

\section{Dependência e políticas sociais na América Latina}

Assim, ao questionar a densidade políticoemancipatória das políticas sociais, na sua condição de mecanismo básico de distribuição das riquezas produzidas coletivamente, torna-se imprescindível a crítica dos mecanismos operados no âmbito do processo de produção de mais-valia, a partir dos quais pode inferir sobre a especificidade das políticas sociais na América Latina.

Inscritas como uma estratégia potente de regulação política do sistema capitalista, as políticas sociais possuem na realidade latino-americana um conjunto de características e determinações absolutamente específicas, delineadas pela sua formação social de tipo capitalista nos marcos do subdesenvolvimento, que, mais do que em qualquer outro contexto, desnudam os limites das soluções reformistas e pseudo-integradoras, nos moldes do que hoje se atribui às mal denominadas políticas de "inclusão social".

No Brasil, e na América Latina em geral, as históricas estruturas de poder político e econômico estabeleceram padrões extremamente injustos e assimétricos de usufruto da riqueza, além de processos cada vez mais adversos de acesso ao trabalho. No caso das formações sociais periféricas do sistema capitalista mundial, as modalidades de acumulação e de exploração da força de trabalho sobrepõem novas contradições à já conhecida impossibilidade do capitalismo de organizar de forma clássica os mercados - com acesso quase-pleno ao trabalho e certo nível de renda - na proporção de seu desenvolvimento, reproduzindo em escala crescente a tendência ao pauperismo. Marini (2000, p. 97) captou com precisão esta característica do capitalismo na América Latina:

$O$ desenvolvimento dessa contradição essencial do capitalismo brasileiro o leva a mais total irracionalidade, isto é, expandir a produção, restringindo cada vez mais a possibilidade de criar para ela um mercado nacional, comprimindo os níveis internos de consumo e aumentando constantemente o exército industrial de reserva.

Este é um elemento básico da lógica de modernização capitalista na América Latina ${ }^{5}$ : a forte e contraditória relação de subordinação com o mercado externo. Mesmo no Brasil, onde o desenvolvimento capitalista atingiu estágio mais avançado, quando comparado aos demais países, as tendências para o fortalecimento de uma economia exportadora confirmam o que tem sido uma regra 
muito mais intensa nos países de desenvolvimento relativo menor, como os centro-americanos, por exemplo. Em suma, a atual fase de acumulação de capital na periferia capitalista latino-americana indica de maneira clara que o mercado interno perde dinamismo para o mercado externo, razão pela qual os direitos sociais são considerados como "custos" e necessitam, portanto, desaparecer ${ }^{6}$.

De partida os países ingressaram no circuito capitalista internacional em condições de inferioridade competitiva evidentes, e até hoje insuperáveis, não somente pela tardia modernização, com reduzido alcance no desenvolvimento das forças produtivas (a partir da década de 1930), mas pela conseqüentemente atrasada participação no mercado mundial. A alternativa adotada pelas classes dominantes latino-americanas para compensar esse déficit tem sido a da superexploração do trabalho, com a intensificação dos processos de extração de mais-valia (na sua forma absoluta e relativa combinadas e o fundo de acumulação) possíveis, sobretudo, pelo rebaixamento salarial e pelo elevado índice de desemprego e subemprego.

Esse modelo econômico - periférico e dependente revela a situação do país e da região: a classe trabalhadora na América Latina (que seria o sujeito de direitos num país central) é composta por um expressivo contingente de trabalhadores informais e de desempregados, para os quais não há sequer vínculo salarial formal nem muito menos acesso à proteção social, decorrentes da sociedade salarial. Enfim, para a grande maioria da população, pobreza e miséria vêm acompanhadas da omissão do Estado, expressa, sobretudo, na ausência de políticas sociais, ou, na maioria das vezes, num tipo determinado de política social, cujo horizonte não pode ser pretensioso em termos sociais e políticos e no qual todo radicalismo deve ser combatido, seja em termos da composição do gasto social seja em função da dimensão emancipadora que elas poderiam conter. Para ir mais longe nesse quadro, deve-se lembrar que o atual estágio de produção e de acumulação de riquezas para a região, conforme diretrizes do FMI, é em si mesmo a principal razão do empobrecimento e aumento dos processos de desigualdade social. O desenho das políticas sociais subordinadas a esta lógica reproduz igualmente as orientações desde fora, e o esboço de proteção social permitido não vai além das ações focalistas e pontuais somente ofertadas nas situações extremas.

A incipiência dos direitos sociais, diferentemente do que se tem habitualmente considerado como decorrente das restrições orçamentárias e da sua institucionalidade burocratizante, ou como produto da incapacidade política dos povos latino-americanos de defenderem seus interesses coletivos, encontra-se no centro mesmo da luta de classes, mas com uma dimensão adicional. A construção de políticas sociais nos Estados latino-americanos encontra-se obstaculizada pela perpetuação da dependência:
A diferença do que acontece nos países capitalistas centrais, onde a atividade econômica está sujeita à relação existente entre as taxas internas de mais-valia e de investimento, nos países dependentes o mecanismo econômico básico deriva da relação exportação-importação: ainda que se obtenha no interior da economia, a mais-valia se realiza na esfera do mercado externo mediante a atividade de exportação, e se traduz em receitas que se aplicam, em sua maior parte, em importações. A diferença entre o valor da exportação e das importações, isto é, o excedente aplicável, sofre, pois, a ação direta de fatores externos à economia nacional (MARINI, 1999, p.115).

No atual ciclo de dependência, o endividamento público vem a se somar como elemento de dominação burguesa junto ao Estado latino-americano, intensificando a captura dos governos aos interesses da aristocracia financeira, que, a partir dos problemas da acumulação, tiveram a capacidade de "[...] avançar ainda mais na transformação da profunda crise social em uma necessidade de Estado" (OURIQUES, 2001, p. 36). É por esta razão que "[...] a cada nova tentativa de 'estabilizar a economia' novas dívidas são incorporadas pelo Estado, aprofundando a dependência e impedindo-o de praticar políticas sociais. Com efeito, estas perderam sentido em função da opção recolonizadora da elite na América Latina" (OURIQUES, 2001, p. 38).

A partir da crítica marxista, iluminada pela teoria da dependência, um núcleo de determinações ganha enorme relevância, em função da natureza da extração da maisvalia por meio da superexploração da força de trabalho. O alcance e o escopo das políticas sociais são restringidos por propósitos sensivelmente distintos das políticas sociais nos países centrais. Como afirma Marini (2000, p. 134), "Na economia exportadora latino-americana, as coisas se dão de outra maneira. Como a circulação se separa da produção e se efetua basicamente no âmbito do mercado externo, o consumo individual do trabalhador não interfere na realização do produto."

Assim, as sucessivas ondas modernizantes impulsionadas de fora para dentro e aplicadas sem reservas a partir do Estado latino-americano não somente são incapazes de resolver os problemas da desigualdade e da injustiça, senão que são precisamente as causas pelas quais estas características se perpetuam sem solução definitiva em curto prazo.

\section{0 horizonte da latinogmericanizaçăo das políticas sociais}

Pode-se dizer que está em curso um importante processo de mobilização coletiva, com altos níveis de 
radicalização política, em busca da criação de um regime de propriedade social e coletiva.

O novo cenário latino-americano oferece fortes indícios de nossa hipótese, pois, a partir dos protestos populares, que em dezembro de 2001 permitiram uma saída popular à crise Argentina, assistimos na região à ascensão da mobilização de massas das classes subalternas em defesa de melhores condições de vida e trabalho. Logo, foi possível observar que no Equador, na Bolívia, na Venezuela, entre outros países, esta decidida atuação em defesa de direitos básicos superou o tradicional limite estabelecido pelas políticas sociais e exigiu uma disputa muito mais clara pelo excedente econômico. É por esta razão que governos, como os dos presidentes Evo Morales ou Hugo Chávez, encabeçaram o protesto popular e exigiram um novo patamar de política social onde a propriedade privada - inicialmente a estrangeira - e os recursos oriundos da propriedade estatal sobre recursos naturais, configuram um novo ponto de partida para novas políticas sociais. Observe-se o contraste com a situação brasileira onde a economia exportadora ganhou legitimidade social que se expressa no orgulho de superávits comerciais fantásticos os quais, não obstante, não permitem volume maior de recursos para políticas sociais. Quando somamos o superávit comercial aos inéditos superávits fiscais, observamos que a soma de recursos no Brasil é muito maior do que em qualquer país latino-americano, incluindo aqui os que se beneficiam do aumento dos preços de petróleo. Sem embargo, no Brasil, a lógica das migalhas dá o tom das políticas sociais.

O movimento popular ainda não se deu conta do fato de que a conjuntura econômica e o ciclo dos negócios permitem, e inclusive exigem, um novo nível de combate em defesa de seus direitos. Afinal, nenhuma autoridade pode alegar que no Brasil faltam recursos para atender demandas de habitação, assistência social, saúde ou educação. Trata-se, aqui, de enfrentar o limite político dos movimentos sociais e sua timidez ideológica e organizativa para enfrentar o caráter de classe do Estado e as limitações políticas de um governo que atende prioritariamente a valorização do capital.

Se preferirmos examinar mais de perto as experiências organizadas diretamente no campo das políticas sociais, um dado precioso precisa ser aferido. Trata-se da experiência de organização do protagonismo popular, na perspectiva de socialização das estruturas de poder político, capazes de afetar, em favor das maiorias, as decisões vitais no espaço dos direitos sociais, para muito além do que se tem pleiteado como participação social.

As estratégias participacionistas, sabemos, por si só, não são portadoras de capacidade transformadora, até porque encontram uma confortável acolhida por parte das agências burocráticas estatais e dos organismos multilaterais que se ocupam de influir na orientação e composi- ção do gasto social público dos países latino-americanos, como Banco Interamericano de Desenvolvimento (BID) e Banco Mundial. Tanto o Programa Nacional de Solidaridad (Pronasol), no México, como o Programa Comunidade Solidária, no Brasil, são exemplos desta orientação. Levados a cabo ao longo dos anos 90, produziram um alto custo para a sociedade, pois o reverso da moeda da participação tão exaltada era a desresponsabilização estatal e a precarização dos serviços básicos, relegados à esfera da solidariedade. Esta, não se pode esquecer, era invocada magicamente, ainda que se apresentasse como uma solidariedade sem sujeitos e sem projetos, que encobria a reedição de potentes mecanismos de subalternização das populações e dos trabalhadores sociais ali atuantes.

Está inaugurada, por outro lado, o reverso desta neofilantropia transclassista. O momento da América Latina hoje, como propõe, por exemplo, o governo bolivariano da Venezuela é "Queremos acabar com a pobreza? Demos poder aos pobres” (FRÍAS, 2004).

O povo em luta, vivendo o curso de socialização da política numa dinâmica revolucionária, malgrado todas as distorções que são atribuídas ao processo venezuelano, pressupõe a população efetivamente organizada, que reivindica e toma, de forma protagônica, as decisões mais fundamentais, com respostas decisivas do governo bolivariano.

Esta advertência é importante porque em grande medida as criticas ácidas ou mesmo certas desconfianças contra o processo liderado pelo Presidente Hugo Chávez Frias, decorre deste fato elementar: para democratizar o Estado venezuelano, as forças populares deverão conquistar maior grau de autonomia nacional [...]. Esta condição geral a todo processo de democratização passava, nas condições específicas da Venezuela, pelo controle presidencial do excedente econômico, que nos anos anteriores havia sido seqüestrado pela elite nacional/internacional. [...] O ponto central é que na Venezuela a ainda modesta política de subsidios realizada pelo atual governo confere sentido de pátria a milhões e torna a disputa pelo excedente real e favorável às classes populares (OURIQUES, 2005, p. 138,140).

É inquestionável que as políticas sociais na Venezuela, por meio das misiones, estão não só reduzindo a pobreza, mas subsidiando uma nova práxis política, onde a população é protagonista da construção de políticas públicas, muito além dos tradicionais direitos alcançados pela via do mercado capitalista e sancionados pelo Estado burguês.

A combinação entre soberania popular e a luta política radical pela justiça social, sob a salvaguarda do Estado, se este for efetivamente democrático, anunciam pilares vigo- 
rosos sobre os quais se ergue o protesto social e os movimentos organizados hoje na América Latina. Nesta medida, não se espera, nessa saturação do interesse público junto ao Estado e à sociedade, que se diluam as fronteiras e se desmobilize a competência da sociedade para fomentar seus organismos de criação de projetos societários e de hegemonia, nem muito menos se pretende assumir responsabilidades governamentais no campo das políticas públicas e da segurança da nação. Ao contrário,

Revigorar a capacidade de controle social e de contestação política, que tão bem caracterizam a atuação dos movimentos populares e dos institutos de organização classista e partidária, é o que se pretende com a publicização dos mecanismos da política formal, como momento de sintese política dos vários organismos democráticos de base, local de resistência contra burocratização e ocupação corrupta e clientelista do Estado. Um dos desafios da democracia de massas é, assim, resistir aos perigos da involução burocrática, contra os processos degenerativos do autoritarismo sempre latente do patriarcado burguês (PAIVA, 2005, p.125)

Os mecanismos de desmobilização e de subalternização, que descredenciam a socialização do poder junto aos segmentos populares, são fartamente conhecidos. Entretanto, um projeto democrático-radical deve insistir na participação popular como eixo da política pública, sem a qual não se opera a ruptura com a lógica que desabilita o caráter protagônico das massas e que dá sustentação à dominação de classes.

Por esta razão, é desanimadora a constatação da timidez da política social do governo Lula, onde o tema da pobreza, apartado da sua dimensão estrutural, permanece confinado como um problema da esfera do consumo e da estrutura familiar. Por mais que a pobreza seja aguda e na medida em que é uma questão explosiva, o melhor mesmo, ao que parece, é esterilizá-la, sobrepondo ações diversas e pulverizadas, que não atacam a raiz da questão social. O risco de se atuar na lógica do ajustamento de comportamentos individuais não é pequeno, haja vista o esforço em empreender e divulgar as chamadas condicionalidades para que as famílias tenham acesso aos benefícios.

É grave constatar que, em função de sua opção de classe a favor dos dominantes, o governo Lula não enfrentou os sistemas de privilégios historicamente assentados no poder no país. Por esta razão, perpetua-se a indiferença com a luta e os interesses dos trabalhadores e seu projeto de classe, reafirmando-os então como descartáveis, tanto quanto suas necessidades de bem usufruir de trabalho, terra, liberdade e felicidade.
Resignação e renúncia na ação política governamental, para atender o poder das elites, nos idênticos termos em sempre se beneficiaram na América Latina, nada mais é do que a adesão aberta e consciente ao projeto burguês, à dominação do capital. No território da práxis política, ao governo eleito com e por causa do apoio das classes subalternas não cabe outra exigência: ser radicalmente democrático e, assim, contribuir na luta revolucionária e anticapitalista dos povos latino-americanos.

\section{Recebido em 02.05.2006. \\ Aprovado em 01.06.2006.}

\section{Referênciass}

BARAN, P.; SWEEZY, P. Capitalismo monopolista. Rio de Janeiro: Zahar, 1966.

FRÍAS, H. C. Reunião de Chefes de Estado Convocada pelo Presidente do Brasil Luiz Inácio Lula da Silva. Nações Unidas, set. 2004. Mimeografado.

CHESNAIS, F. Introdução geral. In: (Coord.). A mundialização financeira: gênese, custos e riscos. São Paulo: Xamã, 1999, p. 11-33.

FERNANDES, F. Nova República? Rio de Janeiro: Zahar, 1985.

MARX, K. Manuscritos econômicos e filosóficos. São Paulo: Editora Martin Claret, 2002.

MARX, K; ENGELS, F. Manifesto do Partido Comunista. Revisão da tradução e prefácio de José Paulo Netto. São Paulo: Cortez, 1998.

Introdução à crítica da economia política. In: Os pensadores. São Paulo: Abril Cultural, v.XXV, 1974.

Manifesto de lançamento da Associação Internacional dos Trabalhadores. In: neiro: Vitória, v. 1, 1956. Obras Escolhidas. Rio de Ja-

MARINI, R.M. Dialética da dependência. Petrópolis: Vozes, 2000.

Subdesenvolvimento e revolução. In: BARSOTTI, P.; PERICÁS, B. América Latina. História, idéias e revolução. São Paulo: Xamã/NET, 1999.

NETTO, J. P. Prólogo: elementos para uma leitura crítica do Manifesto Comunista. In: MARX, K.; ENGELS, F. Manifesto do Partido Comunista. São Paulo: Cortez, 1998.

Capitalismo monopolista e Serviço Social. São Paulo: Cortez, 1992.

OURIQUES, N. A revolução democrática bolivariana. Uma utopia latino-americana, In: (Org.) Raízes no Libertador. Bolivarianismo e poder popularna Venezuela. Florianópolis: Insular, 2005.

Estado e políticas sociais na América Latina. In: NOGUEIRA, F. M. G. Estado e políticas sociais no Brasil. Cascavel: Edunioeste, 2001.

La teoria marxista de la dependencia. 1995. Tese (Doutorado em Economia) - Universidade Nacional Autonoma do México, México, 1995. 
Modernização capitalista e dependência na América Latina. Disponível em <http://www.ola.cse.ufsc.br/analise/ 20060403 nildo.htm>. Acesso em 14 abr. 2006.

PAIVA, B. O poder popular na Venezuela e a práxis Bolivariana. In: OURIQUES, N. (Org.) Raízes no Libertador. Bolivarianismo e poder popular na Venezuela. Florianópolis: Insular, 2005.

SALAMA, P. Novas formas da pobreza na América Latina, In: GENTILI, P. Globalização excludente. Petrópolis: Vozes/LPP/ Clacso, 2001.

VELOSO, C. Haiti. In: Noites do Norte: ao vivo - Duplo. São Paulo: Universal Music, 2001. Disco 1, faixa 6.

\section{Notas}

1 O Observatório Latino-Americano (OLA/UFSC) é um projeto de pesquisa e extensão numa articulação interdisciplinar dos Departamentos de Economia e Serviço Social, vinculado ao Centro Sócio-Econômico, também integrado pelas jornalistas Elaine Tavares e Raquel Moysés, e por estudantes. Tem como objetivo a construção de análises que visam melhor compreender as políticas macroeconômicas e sociais adotadas pelos países da América Latina e o conseqüente movimento de resistência dos povos. A proposta metodológica deste projeto é produzir e divulgar análises críticas sobre a lógica econômica dominante nas relações políticas dos e entre os países latino-americanos, e também disponibilizá-las para a tomada de decisões pelos fóruns acadêmicos e movimentos sociais, nos espaços de construção e mobilização político-intelectual. Assim, o OLA/ UFSC se organiza como uma onda bolivariana de pensamento crítico, que tem como inspiração o sonho de Simón Bolívar de integração dos povos, agora articulado com a busca do socialismo, com vida digna e riquezas repartidas. Cf. <www.ola.cse.ufsc.br>.

2 VELOSO, Caetano (2001).

3 Netto (1998, p.11-2)) ressaltou a capacidade de o Manifesto Comunista antecipar, em mais de um século, um painel da modernidade capitalista. Ainda, segundo o autor, a respeito das crises de superprodução Marx e Engels afirmam: “A sociedade vê-se de repente reconduzida a um estado de momentânea barbárie [...] As relações burguesas tornaramse demasiado estreitas para conterem as riquezas criadas no seu interior. E como a burguesia supera as crises? De um lado, mediante a destruição violenta de grande quantidade de forças produtivas; de outro, pela conquista de novos mercados e pela exploração mais intensa de mercados antigos. E o que isto representa? Representa a preparação de crises mais generalizadas e mais graves e a redução dos meios para evitá-las".

4 Salama (2001, p. 198-199), ao analisar as novas formas de pobreza na América Latina, demonstra que "A evolução da renda dos empregos informais no Brasil tende a estagnar num segundo tempo, desde o fim de 1996, se não a regredir. Paralelamente, a importância relativa destes empregos tende a elevar-se. Esse movimento reflete, portanto, uma participação mais elevada destes empregos informais no total de empregos. [...] Esta tendência para uma informalização acentuada dos empregos pode também ser constatada a partir da análise da evolução do emprego aberto e total. O argumento do desemprego aberto traduz a baixa de empregos informais 'mais informais', uma vez que estes não permitem aos trabalhadores sobreviver e os levam a procurar empregos suplementares que não chegam a encontrar. [...] O crescimento, mesmo vivo, é muito pobre em emprego e os empregos criados são geralmente mais informais do que antes, com remuneração $40 \%$ inferior em média, aos que se beneficiam dos empregos formais."

5 Para um detalhamento desta dinâmica, indica-se Ouriques (2006).

6 Por esta razão podemos entender o discurso oficial tanto de Lula como de Cardoso sobre a "necessidade de uma reforma previdenciária" ou o diminuto gasto com o social, mesmo quando a "economia vai bem" e os superávits são festejados como "glória nacional". Boicotes explícitos ao Sistema Único de Saúde (SUS) permanecem, assustadoramente, sob o governo Lula. A definição do percentual de recursos financeiros federais, previstos na Constituição Federal para o SUS, permanece descumprida pela política econômica. $\mathrm{Na}$ comparação internacional os atuais 3,2\% do PIB, destinados à saúde, representam porcentagem menor do que as de Bolívia, Colômbia, África do Sul, Rússia, Venezuela, Uruguai, Argentina (cerca de 5.12\%), Cuba (6,25\%), EEUU (6,2\%) Japão, Inglaterra, Austrália, Portugal, Itália, Canadá, França, Alemanha (8,1\%). Em termos de financiamento, os valores são expressivos, cerca de R $\$ 2,3$ bilhões representam a diferença acumulada pelo não cumprimento por parte do governo federal da EC. 29 nos anos de 2001 a 2005, porém só no governo Lula este déficit acumula a cifra de $\mathrm{R} \$ 1.832 .000,00$.

\section{Beatriz Augusto de Paiva}

biapaiva@cse.ufsc.br

Departamento de Serviço Social

\section{Nildo Domingos Ouriques}

nildo@cse.ufsc.br

Departamento de Economia

\section{Centro Sócio-Econômico}

Universidade Federal de Santa Catarina

Campus Univ. Reitor João David Ferreira Lima

Trindade - Florianópolis - Santa Catarina

CEP: 88010-970 